\title{
Relevance of unilateral and bilateral sexual polyploidization in relation to intergenomic recombination and introgression in Lilium species hybrids
}

\author{
Nadeem Khan · Rodrigo Barba-Gonzalez • \\ M. S. Ramanna - Paul Arens • \\ Richard G. F. Visser · Jaap M. Van Tuyl
}

Received: 3 April 2009/Accepted: 30 June 2009/Published online: 11 July 2009

(C) The Author(s) 2009. This article is published with open access at Springerlink.com

\begin{abstract}
Sexual polyploids were induced in diploid $(2 n=2 x=24)$ interspecific F1 hybrids of Longiflorum $\times$ Asiatic $(\mathrm{LA})$ and Oriental $\times$ Asiatic $(\mathrm{OA})$ Lilium hybrids by backcrossing to Asiatic (AA) parents as well as by sib-mating of the F1 LA hybrids. A majority of the $\mathrm{BC} 1$ progenies were triploid and the progenies from sib-mating were tetraploid or near tetraploids. Genomic in situ hybridization (GISH) technique was applied to assess the intergenomic recombination in the $\mathrm{BC} 1$ populations of $\mathrm{LA}$ and $\mathrm{OA}$ hybrids obtained after unilateral sexual polyploidization. A total of $63 \mathrm{LA}(\mathrm{LA} \times \mathrm{AA}$ and AA $\times \mathrm{LA})$ and 53 OA hybrids were analysed. LA hybrids were originated through the functioning of $2 n$ gametes either as $2 n$ eggs or $2 n$ pollen while those of OA hybrids originated through functional $2 n$ pollen of diploid OA genotype. In both type of crosses, a majority of the progenies had originated through First Division Restitution (FDR) mechanism of functional
\end{abstract}

N. Khan $(\bowtie) \cdot$ M. S. Ramanna · P. Arens ·

R. G. F. Visser · J. M. Van Tuyl

Plant Breeding, Wageningen University and Research

Centre, P.O. Box 16, 6700 AA Wageningen,

The Netherlands

e-mail: nadeem.khan@wur.nl;

khan_m_nadeem@yahoo.com

R. Barba-Gonzalez

Centro de Investigacion y Asistencia en Tecnologia y

Diseño del Estado de Jalisco, A.C. Biotecnología,

Vegetal Av. Normalistas \# 800, Colinas de la Normal,

44270 Guadalajara, Jalisco, Mexico
$2 n$ gamete either with or without a cross over. However, there were nine LA- and four OA-genotypes where Indeterminate Meiotic Restitution (IMR) was the mechanism of $2 n$ gamete formation. Based on GISH, total amount of introgression of Longiflorum and Oriental genome into Asiatic genome was determined. Most of the BC progenies exhibited recombination and the amount of recombination was higher in LA hybrids as compared to OA hybrids. Intergenomic recombination was also determined cytologically in the 16 plants of sib-mated LA hybrids where both parents had contributed $2 n$ gametes. Based on these results the nature of interspecific lily hybrids obtained from uni- and bilateral sexual polyploidization leading to allotriploid and allotetraploid formation is discussed in the context of introgression and intergenomic recombination.

Keywords $2 n$ gametes - Allopolyploids · Back cross progenies - GISH · Homoeologous recombination · Lily

\section{Introduction}

Sexual production of polyploids involve the fusion of two gametes, one or both of them contributing the somatic or unreduced number of chromosomes to the progeny. Depending on the parental contribution, the sexual polyploidization is either unilateral or 
bilateral (Mendiburu and Peloquin 1976). Normal meiosis in germ cells (pollen- or embryo sac mother cells) results in the formation of four haploid $(n)$ gametes following regular chromosomes association and disjunction. On the other hand, $2 n$ gametes originate due to deviating meiosis in plants. The process that leads to $2 n$ gamete formation is called meiotic nuclear restitution that occurs either during micro- or megasporogenesis. Depending on the particular meiotic stages at which nuclear restitution occurs, different restitution mechanisms have been recognized, viz., first division restitution (FDR), second division restitution (SDR) (Mok and Peloquin 1972; Ramanna 1979) indeterminate meiotic restitution (IMR) (Lim et al. 2001), and post meiotic restitution (PMR) (Bastiaanssen et al. 1998).

The formation of $2 n$ gametes is a common phenomenon in angiosperms (de Wet 1980) which are thought to have played a most important role in the origin and evolution of polyploid series (Harlan and de Wet 1975; Jackson 1976). The sexual polyploidization using $2 n$ gametes not only increases the numbers of genomes in the progeny but it also contributes towards the achievement of genetic variation in the progenies (Ramanna and Jacobsen 2003; Barba-Gonzalez et al. 2005). Furthermore, it also represents the convergence of variability from divergent genotypes into a single individual resulting in heterosis (Ortiz 1997). These two characteristics make sexual polyploidization superior to the somatic doubling of chromosomes, which only increase the number of respective chromosomes without creating any genetic variation in the progenies. Breeders of many vegetatively propagated crops have been taking advantage of the spontaneously occurring $2 n$ gametes for introgressing genes from wild diploid species to their cultivated polyploid crops through ploidy manipulations (Peloquin and Ortiz 1992). The usefulness of polyploids for crop improvement that originate through the functioning of $2 n$ gametes has been demonstrated in some of the crops like potato (Mendiburu and Peloquin 1971; Mendiburu et al. 1974), alfalfa (Bingham 1980; Veronesi et al. 1986), red clover (Parrott and Smith 1984; Smith et al. 1985), blueberry (Lyrene et al. 2003), blackberry (Hall 1990), cassava (Ogburia et al. 2002), peanuts (Stalker and Moss 1987), strawberry (Bringhurst and Voth 1984), sugarcane (Bremer 1961), sweet potato (Becerra Lopez-Lavalle and Orjeda 2002) and banana (Ortiz and Vuylsteke 1995).
The species of the genus Lilium constitute the most important cut flower crops in The Netherlands. However, most of the cultivars have interspecific origin within three different taxonomic sections. For example, the widely grown cultivars of Lilium belong to Longiflorum (L-genome), Asiatic (A-genome) and Oriental (O-genome) hybrids derived from sections Leucolirion, Sinomartagon and Archelirion, respectively, (Lim et al. 2000). The species Lilium possess a wide range of horticultural traits, such as flower size, shape, colours and their arrangement, different forcing times, variation in stem length and strength. However, the most important amongst these are the resistances to various pathogens which are restricted only to certain hybrids within the different sections.

It is most desirable to combine or introgress some important horticultural traits from different species into a single cultivar. In Lilium, however, it is difficult to obtain F1 interspecific hybrids between species or cultivars that belong to different taxonomic sections. Nearly all the F1 Longiflorum $\times$ Asiatic $(\mathrm{LA})$ and Oriental $\times$ Asiatic $(\mathrm{OA})$ hybrids are sterile. This sterility is due to irregular chromosome paring between the parental genomes during meiosis (Lim et al. 2000; Barba-Gonzalez et al. 2004). Somatic chromosome doubling of the F1 hybrids can produce allotetraploids in which homologous chromosomes can pair and restore fertility. This is one way to overcome the F1-sterility problem (Van Tuyl and De Jeu 1997). However, this method could not contribute much to introgression breeding due to the formation of the so-called "permanent hybrids" as their progenies never segregate for parental characters due to autosyndetic pairing (Ramanna and Jacobsen 2003; Van Tuyl and Lim 2003). On the contrary, intergenomic recombination may occur in sexual polyploids induced through the use of $2 n$ gametes (Ramanna et al. 2003; Ramanna and Jacobsen 2003). Interestingly, some F1 LA and OA hybrids could produce functional $2 n$ pollen to some extent. These $2 n$ pollen producing Oriental $\times$ Asiatic (OA hybrids) and Longiflorum $\times$ Asiatic (LA hybrids) F1 hybrids and their triploid progenies were analysed cytologically (Barba-Gonzalez et al. 2005; Lim et al. 2001). It was found that homoeologous chromosomes pair and recombine to certain extents during $2 n$ pollen formation. The subsequent backcross progenies obtained by back crossing these $2 n$ pollen producing F1 LA and 
OA hybrids with Asiatic parents gave triploid progenies with certain amount of intergenomic recombination (Lim et al. 2001; Barba-Gonzalez et al. 2005). Because $2 n$ pollen were responsible for sexual polyploidization and genetic recombination in interspecific lily hybrids then it is possible that $2 n$ eggs could also perform similarly in the F1 interspecific hybrids. Recently Zhou et al. (2008) showed that some F1 LA hybrids also produced $2 n$ eggs in considerable frequencies which transmitted the intergenomic recombination to certain extent to the subsequent progenies when backcrossed with Asiatic parents.

It was found that F1 interspecific lily hybrids producing $2 n$ gametes results in homoeologous chromosomes recombination in the following generations which ultimately leads to considerable genetic variation (Barba-Gonzalez et al. 2004). This may result in the assembling of complementary characters from different species in to a single genotype in a back cross breeding program in Lilium. By keeping this in view about the nature of lily interspecific hybrids, attempts were made to back cross $2 n$ gametes producing LA and OA parents with Asiatic cultivars. In this way an allotriploid $\mathrm{BC} 1$ interspecific lily hybrids could be achieved. Attempts were also made to cross F1 LA hybrids which produced $2 n$ pollen and $2 n$ eggs $($ LA $\times$ LA). In this way allotetraploid lily interspecific hybrids could be achieved by the union of unreduced gametes from both parents. Until now there have been no cytogenetic reports for the occurrence of bilateral sexual polyploidization in interspecific lily hybrids.

The objective of this work was to evaluate the probable consequences of unilateral and bilateral sexual polyploidization cytologically and to discuss the prospects of unilateral and bilateral sexual polyploidization in interspecific lily hybrids. Furthermore, the studies have been elaborated to illustrate how a backcross breeding program enables the transfer of L- and O-genome into A-genomes through functional $2 n$ eggs and $2 n$ pollen, respectively. The GISH approach has been used here for the identification of parental genomes and to estimate the amount of intergenomic recombination in $\mathrm{BC} 1$ progenies of F1 LA and OA hybrids produced from functional $2 n$ eggs and $2 n$ pollen. The usefulness of $2 n$ gametes in generating genetic variation by introgression breeding in Lilium has been discussed using allotriploid BC1 LA and OA hybrids as well as sibmated allotetraploid F2 LA hybrids.

\section{Materials and methods}

Plant material

Most of the diploid F1 Longiflorum $\times$ Asiatic hybrid $(2 n=2 x=24)$ cultivars and some of the triploid interspecific hybrids (Table 1) were supplied by the Dutch lily breeding companies: De Jong Lelies BV, Royal Van Zanten BV, Testcentrum voor Siergewassn BV, Vletter and Den Haan BV and World Breeding BV. However, one F1 LA (024004-5) and Oriental $\times$ Asiatic (951502-1) were developed at Plant Breeding, Wageningen UR (Tables 1, 2). Because the three groups belong to three different taxonomic sections, the cultivars of different sections could be hybridized, or backcrossed, only through special techniques (Van Tuyl et al. 1991; Lim et al. 2001; Barba-Gonzalez et al. 2004). 46 allotriploid $(2 n=3 x=36)$ BC1 LA progeny plants were obtained by backcrossing three different F1 LA hybrids as female parents with nine different Asiatic cultivars to get progeny plants of LA $\times$ AA, indicated as LAA (Table 1) while in reciprocal cross 15 plants were produced where two F1 LA hybrids were used as male parents and backcrossed with three different Asiatic cultivars. In case of OA BC1 progenies, two diploid Asiatic cultivars viz. 'Amarone' and 'Gironde' were used as female parents and crossed with one F1 OA hybrid to get $53 \mathrm{AA} \times \mathrm{OA}$ genotypes (Table 2 ). In order to produce allotetraploid ( $2 n=4 x=48)$ F2 progenies, only one F1 LA hybrids (041502) was used as male parent and crossed with three different F1 LA hybrids (041546, 041548 and 041556 ) as female parents. So a total of 23 genotypes were obtained with a cross combination of LA $\times$ LA and 16 of them were analysed cytologically (Table 3). All the plant material is being maintained vegetatively at Wageningen UR Plant Breeding, Wageningen, The Netherlands.

\section{Flow cytometry}

Flow cytometry was done to evaluate the ploidy level of the $\mathrm{BC} 1$ and $\mathrm{F} 2$ progenies. The germinating embryos were transferred into the propagation 
Table 1 Progeny plants obtained from unilateral sexual polyploidization of LA $\times$ AA and AA $\times$ LA crosses, their ploidy levels, genome composition (number of recombinant chromosomes) and the percentage of genome contribution of the parents

\begin{tabular}{|c|c|c|c|c|c|c|c|c|c|}
\hline \multirow[t]{2}{*}{ Cross } & \multirow[t]{2}{*}{ Genotypes } & \multicolumn{2}{|l|}{ Parents } & \multirow[t]{2}{*}{ Ploidy level } & \multicolumn{2}{|c|}{ Genome composition } & \multicolumn{2}{|c|}{ Genome percentage } & \multirow{2}{*}{$\begin{array}{l}\text { No. of } \\
\text { recombinant } \\
\text { chromosomes }\end{array}$} \\
\hline & & Female & Male & & $\mathrm{L}^{(\mathrm{L} / \mathrm{A})}$ & $\mathrm{A}^{(\mathrm{A} / \mathrm{L})}$ & $\mathrm{L} \%$ & $\mathrm{~A} \%$ & \\
\hline $\mathrm{LA} \times \mathrm{AA}$ & $044525-1$ & 041556 & Mont Blanc & $3 x$ & $12(1)$ & $24(1)$ & 34.8 & 65.2 & 2 \\
\hline $\mathrm{LA} \times \mathrm{AA}$ & 044539-1 & 041558 & Pollyanna & $3 x$ & $12(1)$ & $24(1)$ & 33.3 & 66.7 & 2 \\
\hline $\mathrm{LA} \times \mathrm{AA}$ & $044571-1$ & 041557 & Mont Blanc & $3 x$ & $12(1)$ & $24(2)$ & 33.5 & 66.5 & 3 \\
\hline $\mathrm{LA} \times \mathrm{AA}$ & 062035-1 & 041560 & 061092 & $3 x$ & $12(4)$ & $24(2)$ & 32.81 & 67.19 & 6 \\
\hline $\mathrm{LA} \times \mathrm{AA}$ & $062035-2$ & 041560 & 061092 & $3 x$ & $12(3)$ & $24(3)$ & 32.85 & 67.15 & 6 \\
\hline $\mathrm{LA} \times \mathrm{AA}$ & 062071-1 & 041560 & 061091 & $3 x$ & $12(7)$ & $24(5)$ & 31.38 & 68.62 & 12 \\
\hline $\mathrm{LA} \times \mathrm{AA}$ & 062071-2 & 041560 & 061091 & $3 x$ & 13(9) & $23(5)$ & 33.34 & 66.66 & 14 \\
\hline $\mathrm{LA} \times \mathrm{AA}$ & 062074-1 & 041560 & 061085 & $3 x$ & $12(7)$ & $24(7)$ & 30.66 & 69.34 & 14 \\
\hline $\mathrm{LA} \times \mathrm{AA}$ & 062074-3 & 041560 & 061085 & $3 x$ & $12(6)$ & $24(6)$ & 34.82 & 65.18 & 12 \\
\hline $\mathrm{LA} \times \mathrm{AA}$ & 062074-4 & 041560 & 061085 & $3 x$ & $12(7)$ & $24(7)$ & 36.55 & 63.45 & 14 \\
\hline $\mathrm{LA} \times \mathrm{AA}$ & $065051-2$ & $024004-5$ & 061095 & $3 x$ & $12(2)$ & $24(4)$ & 35.93 & 64.07 & 6 \\
\hline $\mathrm{LA} \times \mathrm{AA}$ & 066828-2 & 041543 & 051072 & $3 x$ & 12 & $24(1)$ & 36.14 & 63.86 & 1 \\
\hline $\mathrm{LA} \times \mathrm{AA}$ & 066828-4 & 041543 & 051072 & $3 x$ & $12(1)$ & $24(1)$ & 33.33 & 66.67 & 2 \\
\hline $\mathrm{LA} \times \mathrm{AA}$ & 066960-4 & 045143 & 031110 & $3 x$ & $12(4)$ & $24(3)$ & 32.37 & 67.63 & 7 \\
\hline $\mathrm{LA} \times \mathrm{AA}$ & 066960-6 & 045143 & 031110 & $3 x$ & 11(4) & $25(3)$ & 32.20 & 67.8 & 7 \\
\hline $\mathrm{LA} \times \mathrm{AA}$ & 066960-8 & 045143 & 031110 & $3 x$ & $12(4)$ & 24 & 29.98 & 70.11 & 4 \\
\hline $\mathrm{LA} \times \mathrm{AA}$ & 066960-9 & 045143 & 031110 & $3 x$ & $12(4)$ & 24 & 30 & 70 & 4 \\
\hline $\mathrm{LA} \times \mathrm{AA}$ & 066960-12 & 045143 & 031110 & $3 x$ & $12(4)$ & $24(2)$ & 33 & 67 & 6 \\
\hline $\mathrm{LA} \times \mathrm{AA}$ & 066960-13 & 045143 & 031110 & $3 x$ & $12(3)$ & $24(4)$ & 34.17 & 65.83 & 7 \\
\hline $\mathrm{LA} \times \mathrm{AA}$ & 066960-14 & 045143 & 031110 & $3 x$ & $12(1)$ & $24(2)$ & 37 & 63 & 3 \\
\hline $\mathrm{LA} \times \mathrm{AA}$ & 066960-16 & 045143 & 031110 & $3 x$ & $12(4)$ & $24(4)$ & 30 & 70 & 8 \\
\hline $\mathrm{LA} \times \mathrm{AA}$ & 066960-20 & 045143 & 031110 & $3 x$ & 11(4) & $25(4)$ & 33.53 & 66.47 & 8 \\
\hline $\mathrm{LA} \times \mathrm{AA}$ & $066963-5$ & 045143 & 031039 & $3 x$ & $12(6)$ & $24(3)$ & 31.37 & 68.63 & 9 \\
\hline $\mathrm{LA} \times \mathrm{AA}$ & 066963-8 & 045143 & 031039 & $3 x$ & $12(3)$ & $24(1)$ & 34.08 & 65.92 & 4 \\
\hline $\mathrm{LA} \times \mathrm{AA}$ & 066994-3 & 041560 & 051073 & $3 x$ & $13(11)$ & $23(9)$ & 33.91 & 66.09 & 20 \\
\hline $\mathrm{LA} \times \mathrm{AA}$ & 066994-4 & 041560 & 051073 & $3 x$ & $12(6)$ & $24(6)$ & 35.60 & 64.4 & 12 \\
\hline $\mathrm{LA} \times \mathrm{AA}$ & 066994-11 & 041560 & 051073 & $3 x$ & $12(8)$ & $24(5)$ & 32.63 & 67.37 & 13 \\
\hline $\mathrm{LA} \times \mathrm{AA}$ & 066994-12 & 041560 & 051073 & $3 x$ & $12(5)$ & $24(8)$ & 35.96 & 64.04 & 13 \\
\hline $\mathrm{LA} \times \mathrm{AA}$ & 066995-1 & 041560 & 031040 & $3 x$ & $12(5)$ & $24(3)$ & 37.01 & 62.99 & 8 \\
\hline $\mathrm{AA} \times \mathrm{LA}$ & 044595-1 & Pollyanna & 041519 & $3 x$ & $10(2)$ & $26(3)$ & 29.65 & 70.5 & 5 \\
\hline $\mathrm{AA} \times \mathrm{LA}$ & 044595-4 & Pollyanna & 041519 & $3 x$ & 12 & 24 & 33 & 67 & 0 \\
\hline $\mathrm{AA} \times \mathrm{LA}$ & 044601-1 & Mont Blanc & 041502 & $3 x$ & $12(1)$ & $24(2)$ & 34.3 & 65.7 & 3 \\
\hline $\mathrm{AA} \times \mathrm{LA}$ & 044601-2 & Mont Blanc & 041502 & $3 x$ & $10(2)$ & $26(4)$ & 31.04 & 68.96 & 6 \\
\hline $\mathrm{AA} \times \mathrm{LA}$ & $044601-3$ & Mont Blanc & 041502 & $3 x-1$ & 11 & $24(1)$ & 32.0 & 68 & 1 \\
\hline $\mathrm{AA} \times \mathrm{LA}$ & 044601-4 & Mont Blanc & 041502 & $3 x$ & $12(1)$ & $24(1)$ & 33.0 & 67.0 & 2 \\
\hline $\mathrm{AA} \times \mathrm{LA}$ & 044601-5 & Mont Blanc & 041502 & $3 x-1$ & $11(1)$ & 24 & 30.5 & 69.5 & 1 \\
\hline $\mathrm{AA} \times \mathrm{LA}$ & 044601-6 & Mont Blanc & 041502 & $3 x$ & $12(2)$ & $24(1)$ & 31.6 & 68.4 & 3 \\
\hline $\mathrm{AA} \times \mathrm{LA}$ & $044601-7$ & Mont Blanc & 041502 & $3 x$ & 12 & $24(3)$ & 33.7 & 66.3 & 3 \\
\hline $\mathrm{AA} \times \mathrm{LA}$ & $044601-8$ & Mont Blanc & 041502 & $3 x+1$ & $13(2)$ & $24(1)$ & 34.5 & 65.5 & 3 \\
\hline $\mathrm{AA} \times \mathrm{LA}$ & 044638-1 & Vivaldi & 041502 & $3 x-1$ & 11(1) & $24(1)$ & 32.31 & 67.9 & 2 \\
\hline $\mathrm{AA} \times \mathrm{LA}$ & $044638-2$ & Vivaldi & 041502 & $3 x$ & 10 & $26(2)$ & 30.25 & 69.75 & 2 \\
\hline $\mathrm{AA} \times \mathrm{LA}$ & 044638-3 & Vivaldi & 041502 & $3 x$ & $10(1)$ & $26(3)$ & 31.4 & 68.9 & 4 \\
\hline
\end{tabular}


Table 1 continued

\begin{tabular}{|c|c|c|c|c|c|c|c|c|c|}
\hline \multirow[t]{2}{*}{ Cross } & \multirow[t]{2}{*}{ Genotypes } & \multicolumn{2}{|l|}{ Parents } & \multirow[t]{2}{*}{ Ploidy level } & \multicolumn{2}{|c|}{ Genome composition } & \multicolumn{2}{|c|}{ Genome percentage } & \multirow{2}{*}{$\begin{array}{l}\text { No. of } \\
\text { recombinant } \\
\text { chromosomes }\end{array}$} \\
\hline & & Female & Male & & $\mathrm{L}^{(\mathrm{L} / \mathrm{A})}$ & $\mathrm{A}^{(\mathrm{A} / \mathrm{L})}$ & $\mathrm{L} \%$ & $\mathrm{~A} \%$ & \\
\hline $\mathrm{AA} \times \mathrm{LA}$ & $044638-4$ & Vivaldi & 041502 & $3 x$ & 12 & 24 & 33.3 & 66.7 & 0 \\
\hline $\mathrm{AA} \times \mathrm{LA}$ & $044638-6$ & Vivaldi & 041502 & $3 x$ & 12 & 24 & 33.3 & 66.7 & 0 \\
\hline $\mathrm{LA} \times \mathrm{AA}$ & $041551^{*}$ & & & $3 x$ & $12(1)$ & $24(1)$ & 33.3 & 66.7 & 2 \\
\hline $\mathrm{LA} \times \mathrm{AA}$ & $041552 *$ & & & $3 x$ & $12(2)$ & $24(2)$ & 32.7 & 67.3 & 4 \\
\hline $\mathrm{LA} \times \mathrm{AA}$ & $041553 *$ & & & $3 x$ & $12(1)$ & $24(2)$ & 35.4 & 64.6 & 3 \\
\hline $\mathrm{LA} \times \mathrm{AA}$ & $041554 *$ & & & $3 x$ & $12(1)$ & 24 & 31.7 & 68.3 & 1 \\
\hline $\mathrm{LA} \times \mathrm{AA}$ & $041555^{*}$ & & & $3 x+1$ & $12(1)$ & 25 & 31.9 & 68.1 & 1 \\
\hline $\mathrm{LA} \times \mathrm{AA}$ & $041568 *$ & & & $3 x$ & 12 & 24 & 33.3 & 66.7 & 0 \\
\hline $\mathrm{LA} \times \mathrm{AA}$ & $041569 *$ & & & $3 x$ & $12(1)$ & $24(1)$ & 33.3 & 66.7 & 2 \\
\hline $\mathrm{LA} \times \mathrm{AA}$ & $041571 *$ & & & $3 x$ & $12(2)$ & $24(2)$ & 32.3 & 67.7 & 4 \\
\hline $\mathrm{LA} \times \mathrm{AA}$ & $041572 *$ & & & $3 x+1$ & $13(2)$ & $24(1)$ & 33.8 & 66.2 & 3 \\
\hline $\mathrm{LA} \times \mathrm{AA}$ & $041573 *$ & & & $3 x$ & $12(1)$ & $24(1)$ & 33.3 & 66.7 & 2 \\
\hline $\mathrm{LA} \times \mathrm{AA}$ & $041574 *$ & & & $3 x$ & $12(1)$ & $24(1)$ & 33.3 & 66.7 & 2 \\
\hline $\mathrm{LA} \times \mathrm{AA}$ & $041575^{*}$ & & & $3 x$ & $12(1)$ & $24(1)$ & 33.3 & 66.7 & 2 \\
\hline $\mathrm{LA} \times \mathrm{AA}$ & 041576* & & & $3 x$ & 12 & 24 & 33.3 & 66.7 & 0 \\
\hline $\mathrm{LA} \times \mathrm{AA}$ & $041578 *$ & & & $3 x$ & $12(1)$ & 24 & 31.4 & 68.6 & 1 \\
\hline $\mathrm{LA} \times \mathrm{AA}$ & $041579 *$ & & & $3 x$ & 12 & 24 & 33.3 & 66.7 & 0 \\
\hline $\mathrm{LA} \times \mathrm{AA}$ & $041580 *$ & & & $3 x$ & $12(3)$ & $24(2)$ & 31.2 & 68.8 & 5 \\
\hline $\mathrm{LA} \times \mathrm{AA}$ & $041581 *$ & & & $3 x$ & 12 & $24(3)$ & 38.2 & 61.8 & 3 \\
\hline $\mathrm{LA} \times \mathrm{AA}$ & $041582 *$ & & & $3 x$ & 12 & 24 & 33.3 & 66.7 & 0 \\
\hline $\mathrm{LA} \times \mathrm{AA}$ & $041583^{*}$ & & & $3 x$ & $12(1)$ & $24(1)$ & 33.2 & 66.8 & 2 \\
\hline
\end{tabular}

* Names of the cultivars and their parentage are not mentioned due to proprietary considerations

medium and allowed to grow until leaves developed. One leaf or scale was collected from each seedling for testing ploidy level as described by Van Tuyl and Boon (1997).

Mitotic chromosome preparation

For mitotic metaphase chromosome analysis, root tips were collected early in the morning, incubated in $0.7 \mathrm{mM}$ cycloheximide solution for $4-6 \mathrm{~h}$ and then fixed in ethanol-acetic acid (3:1) solution for 12-24 h and stored at $4^{\circ} \mathrm{C}$ until use. The root tips were washed in distilled water and incubated in a pectolytic enzyme mixture containing $0.2 \%(\mathrm{w} / \mathrm{v})$ pectyolase Y23, $0.2 \%(\mathrm{w} / \mathrm{v})$ cytohelicase and $0.2 \%(\mathrm{w} / \mathrm{v})$ cellulase RS in $10 \mathrm{mM}$ citrate buffer $(\mathrm{pH} 4.5)$ at $37^{\circ} \mathrm{C}$ for about $1 \mathrm{~h}$. Squash preparations were made in a drop of $45 \%$ acetic acid and frozen in liquid nitrogen. The cover slips were removed by using a razor blade. The slides were then dehydrated in absolute ethanol and air dried.
Genomic in situ hybridization (GISH)

Genomic DNA of Longiflorum cultivar White Fox and Oriental cultivar Sorbonne were used as probes and labeled with either Digoxigenin-11-dUTP or Biotin-16-dUTP by a standard nick translation protocol (Roche Diagnostics GmbH, Mannheim, Germany). Total genomic DNA was extracted with the CTAB method (Rogers and Bendich 1988). The GISH procedure and mitotic chromosome spreads were performed as described by Lim et al. (2003) and Barba-Gonzalez et al. (2005). Briefly, the hybridization mixture contained $50 \%(\mathrm{v} / \mathrm{v})$ deionized formamide, $10 \%(\mathrm{w} / \mathrm{v})$ sodium dextran sulfate, $2 x \mathrm{SSC}$, $0.25 \%(\mathrm{w} / \mathrm{v})$ sodium dodecyl sulfate, $1-1.5 \mathrm{ng} / \mu \mathrm{l}$ Digoxigenin or Biotin labeled DNA from Longiflorum or Oriental cultivars and $25-100 \mathrm{ng} / \mu \mathrm{l}$ block DNA of Asiatic cultivar. The DNA was denatured by heating the hybridization mixture at $70^{\circ} \mathrm{C}$ for $10 \mathrm{~min}$ followed by incubation in ice for $5 \mathrm{~min}$. The hybridization mixture was then applied on each slide 
Table 2 Progeny plants obtained from unilateral sexual polyploidization of AA $\times$ OA crosses, their ploidy levels, genome composition (number of recombinant chromosomes) and the percentage of genome contribution of the parents

\begin{tabular}{|c|c|c|c|c|c|c|c|c|c|}
\hline \multirow[t]{2}{*}{ Cross } & \multirow[t]{2}{*}{ Genotypes } & \multicolumn{2}{|l|}{ Parents } & \multirow[t]{2}{*}{ Ploidy level } & \multicolumn{2}{|c|}{ Genome composition } & \multicolumn{2}{|c|}{ Genome percentage } & \multirow{2}{*}{$\begin{array}{l}\text { No. of } \\
\text { recombinant } \\
\text { chromosomes }\end{array}$} \\
\hline & & Female & Male & & $\mathrm{O}^{(\mathrm{O} / \mathrm{A})}$ & $\mathrm{A}^{(\mathrm{A} / \mathrm{O})}$ & $\mathrm{O} \%$ & $\mathrm{~A} \%$ & \\
\hline $\mathrm{AA} \times \mathrm{OA}$ & $022538-1$ & Amarone & $951502-1$ & $3 x$ & $12(4)$ & $24(3)$ & 32.64 & 67.36 & 7 \\
\hline $\mathrm{AA} \times \mathrm{OA}$ & $022538-3$ & Amarone & $951502-1$ & $3 x$ & $12(4)$ & $24(2)$ & 31.13 & 68.87 & 6 \\
\hline $\mathrm{AA} \times \mathrm{OA}$ & $022538-5$ & Amarone & $951502-1$ & $3 x$ & $12(3)$ & $24(2)$ & 32.0 & 68.0 & 5 \\
\hline $\mathrm{AA} \times \mathrm{OA}$ & $022538-7$ & Amarone & $951502-1$ & $3 x$ & $13(3)$ & $23(3)$ & 35.07 & 64.93 & 6 \\
\hline $\mathrm{AA} \times \mathrm{OA}$ & $022538-8$ & Amarone & $951502-1$ & $3 x$ & $12(2)$ & $24(2)$ & 32.23 & 67.77 & 4 \\
\hline $\mathrm{AA} \times \mathrm{OA}$ & $022538-9$ & Amarone & $951502-1$ & $3 x$ & $13(2)$ & $23(2)$ & 35.4 & 64.6 & 4 \\
\hline $\mathrm{AA} \times \mathrm{OA}$ & $022538-14$ & Amarone & $951502-1$ & $3 x$ & $12(3)$ & $24(2)$ & 30.5 & 69.5 & 5 \\
\hline $\mathrm{AA} \times \mathrm{OA}$ & 022538-15 & Amarone & $951502-1$ & $3 x$ & $11(1)$ & $25(3)$ & 32.12 & 67.88 & 4 \\
\hline $\mathrm{AA} \times \mathrm{OA}$ & $022538-16$ & Amarone & $951502-1$ & $3 x$ & $12(5)$ & $24(3)$ & 30.22 & 69.78 & 8 \\
\hline $\mathrm{AA} \times \mathrm{OA}$ & 022538-17 & Amarone & $951502-1$ & $3 x$ & $12(1)$ & $24(1)$ & 33.3 & 66.7 & 2 \\
\hline $\mathrm{AA} \times \mathrm{OA}$ & 022604-6 & Gironde & $951502-1$ & $3 x$ & 12 & 24 & 33.3 & 66.7 & 0 \\
\hline $\mathrm{AA} \times \mathrm{OA}$ & 022604-9 & Gironde & $951502-1$ & $3 x$ & $12(1)$ & 24 & 27.0 & 73.0 & 1 \\
\hline $\mathrm{AA} \times \mathrm{OA}$ & 022604-10 & Gironde & $951502-1$ & $3 x$ & 12 & 24 & 33.3 & 66.7 & 0 \\
\hline $\mathrm{AA} \times \mathrm{OA}$ & 022605-1 & Amarone & $951502-1$ & $3 x$ & $12(1)$ & $24(1)$ & 32.00 & 68 & 2 \\
\hline $\mathrm{AA} \times \mathrm{OA}$ & $022605-2$ & Amarone & $951502-1$ & $3 x$ & $12(1)$ & $24(1)$ & 32.02 & 67.98 & 2 \\
\hline $\mathrm{AA} \times \mathrm{OA}$ & $022605-3$ & Amarone & $951502-1$ & $3 x$ & $12(4)$ & $24(3)$ & 20.0 & 80.0 & 7 \\
\hline $\mathrm{AA} \times \mathrm{OA}$ & 022605-4 & Amarone & $951502-1$ & $4 x$ & 12 & 36 & 25 & 75 & 0 \\
\hline $\mathrm{AA} \times \mathrm{OA}$ & 022605-5 & Amarone & $951502-1$ & $3 x$ & $12(1)$ & $24(1)$ & 32.5 & 67.5 & 2 \\
\hline $\mathrm{AA} \times \mathrm{OA}$ & 022605-7 & Amarone & $951502-1$ & $3 x$ & $12(3)$ & $24(3)$ & 29.0 & 71.0 & 6 \\
\hline $\mathrm{AA} \times \mathrm{OA}$ & $022605-8$ & Amarone & $951502-1$ & $3 x$ & $12(2)$ & $24(1)$ & 32.82 & 67.18 & 3 \\
\hline $\mathrm{AA} \times \mathrm{OA}$ & 022605-9 & Amarone & $951502-1$ & $3 x$ & $12(4)$ & $24(3)$ & 34.35 & 65.65 & 7 \\
\hline $\mathrm{AA} \times \mathrm{OA}$ & 022605-10 & Amarone & $951502-1$ & $4 x$ & 12 & 36 & 25 & 75 & 2 \\
\hline $\mathrm{AA} \times \mathrm{OA}$ & 022605-11 & Amarone & $951502-1$ & $3 x$ & $12(1)$ & $24(1)$ & 33.3 & 66.7 & 2 \\
\hline $\mathrm{AA} \times \mathrm{OA}$ & 022605-12 & Amarone & $951502-1$ & $3 x$ & $12(1)$ & $24(1)$ & 33.22 & 66.8 & 2 \\
\hline $\mathrm{AA} \times \mathrm{OA}$ & 022605-13 & Amarone & $951502-1$ & $4 x$ & 11(1) & $37(1)$ & 20.25 & 79.75 & 2 \\
\hline $\mathrm{AA} \times \mathrm{OA}$ & 022605-15 & Amarone & $951502-1$ & $4 x$ & 12 & 36 & 25 & 75 & 0 \\
\hline $\mathrm{AA} \times \mathrm{OA}$ & 022605-16 & Amarone & $951502-1$ & $3 x$ & $12(2)$ & $24(2)$ & 33.3 & 66.7 & 4 \\
\hline $\mathrm{AA} \times \mathrm{OA}$ & 022605-18 & Amarone & $951502-1$ & $3 x$ & $12(2)$ & $24(2)$ & 28 & 72 & 4 \\
\hline $\mathrm{AA} \times \mathrm{OA}$ & 022605-19 & Amarone & $951502-1$ & $3 x$ & $12(4)$ & $24(2)$ & 30.5 & 69.5 & 6 \\
\hline $\mathrm{AA} \times \mathrm{OA}$ & 022605-20 & Amarone & $951502-1$ & $3 x$ & $12(4)$ & $24(2)$ & 31.23 & 67.57 & 6 \\
\hline $\mathrm{AA} \times \mathrm{OA}$ & $022605-21$ & Amarone & $951502-1$ & $3 x$ & $12(4)$ & $24(4)$ & 32.43 & 67.57 & 8 \\
\hline $\mathrm{AA} \times \mathrm{OA}$ & $022605-22$ & Amarone & $951502-1$ & $3 x$ & $12(1)$ & $24(1)$ & 33.3 & 66.7 & 2 \\
\hline $\mathrm{AA} \times \mathrm{OA}$ & $022605-23$ & Amarone & $951502-1$ & $3 x$ & $12(3)$ & $24(2)$ & 31.7 & 68.3 & 5 \\
\hline $\mathrm{AA} \times \mathrm{OA}$ & $022605-24$ & Amarone & $951502-1$ & $3 x$ & $12(3)$ & $24(2)$ & 30.0 & 70.0 & 5 \\
\hline $\mathrm{AA} \times \mathrm{OA}$ & 022605-25 & Amarone & $951502-1$ & $3 x$ & $12(3)$ & $24(2)$ & 31.3 & 68.7 & 5 \\
\hline $\mathrm{AA} \times \mathrm{OA}$ & 022605-27 & Amarone & $951502-1$ & $3 x$ & $12(1)$ & $24(1)$ & 33.33 & 66.7 & 2 \\
\hline $\mathrm{AA} \times \mathrm{OA}$ & $022605-28$ & Amarone & $951502-1$ & $3 x$ & $12(1)$ & 24 & 31.16 & 68.84 & 1 \\
\hline $\mathrm{AA} \times \mathrm{OA}$ & 022605-30 & Amarone & $951502-1$ & $3 x+1$ & $12(2)$ & $25(2)$ & 32.0 & 68 & 4 \\
\hline $\mathrm{AA} \times \mathrm{OA}$ & 022605-31 & Amarone & $951502-1$ & $3 x$ & $12(2)$ & 24 & 29.55 & 70.45 & 2 \\
\hline $\mathrm{AA} \times \mathrm{OA}$ & 022605-32 & Amarone & $951502-1$ & $3 x$ & 12 & 24 & 33.3 & 66.7 & 0 \\
\hline $\mathrm{AA} \times \mathrm{OA}$ & $022605-34$ & Amarone & $951502-1$ & $3 x$ & $12(2)$ & $24(2)$ & 33 & 67 & 4 \\
\hline $\mathrm{AA} \times \mathrm{OA}$ & 022605-35 & Amarone & $951502-1$ & $3 x$ & $12(6)$ & $24(2)$ & 30.83 & 69.17 & 8 \\
\hline
\end{tabular}


Table 2 continued

\begin{tabular}{|c|c|c|c|c|c|c|c|c|c|}
\hline \multirow[t]{2}{*}{ Cross } & \multirow[t]{2}{*}{ Genotypes } & \multicolumn{2}{|l|}{ Parents } & \multirow[t]{2}{*}{ Ploidy level } & \multicolumn{2}{|c|}{ Genome composition } & \multicolumn{2}{|c|}{ Genome percentage } & \multirow{2}{*}{$\begin{array}{l}\text { No. of } \\
\text { recombinant } \\
\text { chromosomes }\end{array}$} \\
\hline & & Female & Male & & $\mathrm{O}^{(\mathrm{O} / \mathrm{A})}$ & $\mathrm{A}^{(\mathrm{A} / \mathrm{O})}$ & $\mathrm{O} \%$ & $\mathrm{~A} \%$ & \\
\hline $\mathrm{AA} \times \mathrm{OA}$ & 022605-36 & Amarone & $951502-1$ & $3 x$ & $12(2)$ & 24 & 29.4 & 70.6 & 2 \\
\hline $\mathrm{AA} \times \mathrm{OA}$ & 022605-37 & Amarone & $951502-1$ & $3 x$ & $12(1)$ & 24 & 31.27 & 68.8 & 1 \\
\hline $\mathrm{AA} \times \mathrm{OA}$ & 022605-38 & Amarone & $951502-1$ & $3 x$ & $12(1)$ & $24(1)$ & 33.3 & 66.7 & 2 \\
\hline $\mathrm{AA} \times \mathrm{OA}$ & 022605-39 & Amarone & $951502-1$ & $3 x$ & $12(2)$ & $24(2)$ & 33.3 & 66.7 & 4 \\
\hline $\mathrm{AA} \times \mathrm{OA}$ & $022605-40$ & Amarone & $951502-1$ & $3 x$ & $12(2)$ & $24(2)$ & 33.3 & 66.7 & 4 \\
\hline $\mathrm{AA} \times \mathrm{OA}$ & $022605-41$ & Amarone & $951502-1$ & $3 x$ & 12 & 24 & 35.96 & 64.04 & 0 \\
\hline $\mathrm{AA} \times \mathrm{OA}$ & 022605-42 & Amarone & $951502-1$ & $3 x$ & $12(1)$ & $24(3)$ & 33 & 67 & 4 \\
\hline $\mathrm{AA} \times \mathrm{OA}$ & 022605-44 & Amarone & $951502-1$ & $3 x$ & $12(1)$ & $24(1)$ & 33.3 & 66.7 & 2 \\
\hline $\mathrm{AA} \times \mathrm{OA}$ & 022605-45 & Amarone & $951502-1$ & $3 x$ & 12 & $24(3)$ & 35.93 & 64.07 & 3 \\
\hline $\mathrm{AA} \times \mathrm{OA}$ & 022605-46 & Amarone & $951502-1$ & $3 x$ & $12(3)$ & $24(3)$ & 36.92 & 63.08 & 6 \\
\hline $\mathrm{AA} \times \mathrm{OA}$ & 022611-4 & Gironde & $951502-1$ & $3 x$ & $12(1)$ & $24(3)$ & 35.96 & 64.04 & 4 \\
\hline
\end{tabular}

Table 3 Progenies obtained from bilateral sexual polyploidization using $2 n$ gamete producing LA hybrids (LA $\times$ LA), their ploidy levels and genome composition (number of recombinant chromosomes)

\begin{tabular}{|c|c|c|c|c|c|c|c|}
\hline \multirow[t]{2}{*}{ Cross } & \multirow[t]{2}{*}{ Genotype } & \multicolumn{2}{|l|}{ Parents } & \multirow[t]{2}{*}{ Ploidy level } & \multicolumn{2}{|c|}{ Genome composition } & \multirow{2}{*}{$\begin{array}{l}\text { Number of } \\
\text { recombinant } \\
\text { chromosomes }\end{array}$} \\
\hline & & Female & Male & & $\mathrm{L}^{(\mathrm{L} / \mathrm{A})}$ & $\mathrm{A}^{(\mathrm{A} / \mathrm{L})}$ & \\
\hline $\mathrm{LA} \times \mathrm{LA}$ & $064525-1$ & 041556 & 041502 & $4 x$ & 23 & 25 & 0 \\
\hline $\mathrm{LA} \times \mathrm{LA}$ & $064525-6$ & 041556 & 041502 & $4 x-4$ & $21(1)$ & $23(2)$ & 3 \\
\hline $\mathrm{LA} \times \mathrm{LA}$ & $064525-7$ & 041556 & 041502 & $4 x-5$ & $21(3)$ & $22(2)$ & 5 \\
\hline $\mathrm{LA} \times \mathrm{LA}$ & $064525-8$ & 041556 & 041502 & $4 x+5$ & $28(3)$ & $25(2)$ & 5 \\
\hline $\mathrm{LA} \times \mathrm{LA}$ & $064525-9$ & 041556 & 041502 & $4 x$ & $22(2)$ & $26(3)$ & 5 \\
\hline $\mathrm{LA} \times \mathrm{LA}$ & $064525-10$ & 041556 & 041502 & $4 x$ & $22(1)$ & $26(1)$ & 2 \\
\hline $\mathrm{LA} \times \mathrm{LA}$ & $064525-13$ & 041556 & 041502 & $4 x$ & $25(3)$ & $23(1)$ & 4 \\
\hline $\mathrm{LA} \times \mathrm{LA}$ & $064525-14$ & 041556 & 041502 & $4 x-1$ & $24(2)$ & $23(1)$ & 3 \\
\hline $\mathrm{LA} \times \mathrm{LA}$ & $064525-15$ & 041556 & 041502 & $4 x-3$ & $21(2)$ & 24 & 2 \\
\hline $\mathrm{LA} \times \mathrm{LA}$ & $064525-16$ & 041556 & 041502 & $4 x$ & $25(4)$ & $23(1)$ & 5 \\
\hline $\mathrm{LA} \times \mathrm{LA}$ & $064525-17$ & 041556 & 041502 & $4 x$ & 22 & 26 & 0 \\
\hline $\mathrm{LA} \times \mathrm{LA}$ & $064525-18$ & 041556 & 041502 & $4 x+1$ & 22 & $27(1)$ & 1 \\
\hline $\mathrm{LA} \times \mathrm{LA}$ & 064525-19 & 041556 & 041502 & $4 x$ & $23(2)$ & $25(1)$ & 3 \\
\hline $\mathrm{LA} \times \mathrm{LA}$ & $064525-20$ & 041556 & 041502 & $4 x$ & $25(3)$ & $23(4)$ & 7 \\
\hline $\mathrm{LA} \times \mathrm{LA}$ & 064534-1 & 041546 & 041502 & $4 x$ & $25(5)$ & $23(5)$ & 10 \\
\hline $\mathrm{LA} \times \mathrm{LA}$ & $064536-2$ & 041548 & 041502 & $4 x-1$ & $23(1)$ & 24 & 1 \\
\hline
\end{tabular}

$(40 \mu \mathrm{l})$. The preparations were denatured immediately prior to incubate at $80^{\circ} \mathrm{C}$ for $5 \mathrm{~min}$. After overnight hybridization at $37^{\circ} \mathrm{C}$ in a humid chamber the slides were washed at room temperature in $2 x$ SSC for 15 min followed by stringent washing with $0.1 \mathrm{x}$ SSC for $30 \mathrm{~min}$ at $42^{\circ} \mathrm{C}$. Digoxigenin labelled DNA was detected with antidigoxigeninfluorescein raised in sheep (Boehringer, Mannheim, Germany) and amplified with fluorescein anti-sheep immunoglobulin raised in rabbit (Vector Laboratories). Biotin labelled DNA was detected with CY-3 conjugated streptavidin and amplified with biotinylated goat-antistreptavidine (Vector laboratories). Preparations were analysed using Zeiss Axiophot epifluorescence microscope and photographed by Canon digital camera. For each plant, the total number of chromosomes and the number of recombinant points were determined. 
Chromosome identification, measurement and determination of genome contribution

For karyotyping in both genomes ( $\mathrm{L}$ and A), chromosomes are arranged in sequence of decreasing short arm length according to Stewart (1947). Some of the chromosomes in the somatic karyotype could be identified on the basis of total length and arm ratios (e.g., 1, 2, 3 10, 11 and 12). In other cases, however, the differences in the lengths of short arms were used for identification. By identifying recombination sites analysed by GISH, the same chromosome could be accurately identified in 5-10 cells and compared with the previous and the succeeding chromosomes in the karyotype. Furthermore, the centromeric index (shortarm length/short-arm length + long-arm length) and the relative chromosome length index (individual chromosome length/total length of all chromosomes) were determined for all genotypes (Barthes and Ricroch 2001). For the measurements and determination of genome contribution, images of mitotic metaphase chromosomes from each genotype were collected and were measured in micrometers $(\mu \mathrm{m})$. The contribution of the amount of both $\mathrm{L}$ and $\mathrm{A}$ genomes (in terms of percentage) in $\mathrm{BC}$ progenies was determined using the computer program MicroMeasure (Reeves and Tear 2000; http://www.colostate.edu/ Depts/Biology/MicroMeasure).

\section{Results}

Unilateral sexual polyploidization

The number of genotypes of both LA and OA hybrids that produced notable frequencies of either $2 n$ eggs or $2 n$ pollen were generally few and in none of the cases any single genotype produced both types gametes. Therefore, unilateral sexual polyploidization was carried out by using the $2 n$ gamete producing genotypes either as male or female parents by backcrossing with Asiatic parents. For bilateral sexual polyploidization, however, it was necessary to cross (sib-mate) the genotypes that produced $2 n$ eggs with those that produced $2 n$ pollen. In the case of LA hybrids, there were genotypes that produced either $2 n$ eggs or $2 n$ pollen. This was not the case with OA hybrids in which only one genotype that produced $2 n$ pollen was available. For this reason bilateral sexual polyploidization was possible in the case of LA hybrids but not in the case of OA hybrids.

Production of progenies from LA $\times$ AA and reciprocal

During present study, efforts were made to produce a fairly large number of backcross progenies from unilateral sexual polyploidization. In case of LA hybrids progenies were obtained by using both $2 n$ eggs and $2 n$ pollen. Three different F1 LA hybrids were used as female parents and backcrossed with nine different Asiatic cultivars to get $\mathrm{LA} \times \mathrm{AA}$ (LAA) progeny plants (Table 1). A total of 46 allotriploid $(2 n=3 x=36)$ and two aneuploid $(2 n=3 x=36+1)$ BC1 LA progeny plants were obtained. This indicated that it is possible to produce a large number of progenies by using $2 n$ eggs of F1 LA hybrids. In the reciprocal cross 15 plants were produced where three F1 LA genotypes were used as male parents and backcrossed with three different Asiatic cultivars. Eleven of these plants were triploid $(2 n=3 x=36)$ while four of them had aneuploid condition $(2 n=3 x=36+1$ or -1$)$. The occurrence of allotriploids in AA $\times$ LA crosses indicated that F1 LA hybrids produced functional $2 n$ pollen. Besides the progenies obtained from the use of $2 n$ eggs and $2 n$ pollen from LA hybrids in the present study, the genome constitution of some of the cultivars supplied by the lily breeders are also included in Table 1 (19 genotypes at the end of the Table 1). These had resulted from unilateral sexual polyploidization at the breeding companies (for confidential reasons, the names of the cultivars and their parentage are not mentioned in the Table 1).

\section{Production of progenies of AA $\times$ OA crosses}

In order to generate OA progeny through unilateral sexual polyploidization from OA hybrids, only one F1 OA hybrid was used as a male parent and backcrossed to two different Asiatic cultivars to get $\mathrm{AA} \times \mathrm{OA}$ types of $\mathrm{BC} 1$ progenies. Although various parental combinations were tried (data not shown) to get allotriploid progenies through unilateral sexual polyploidization, there was no success. This was due to the frequency of $2 n$ pollen produced by different F1 OA hybrids which was not sufficient for a successful backcross. A total of 53 plants were 

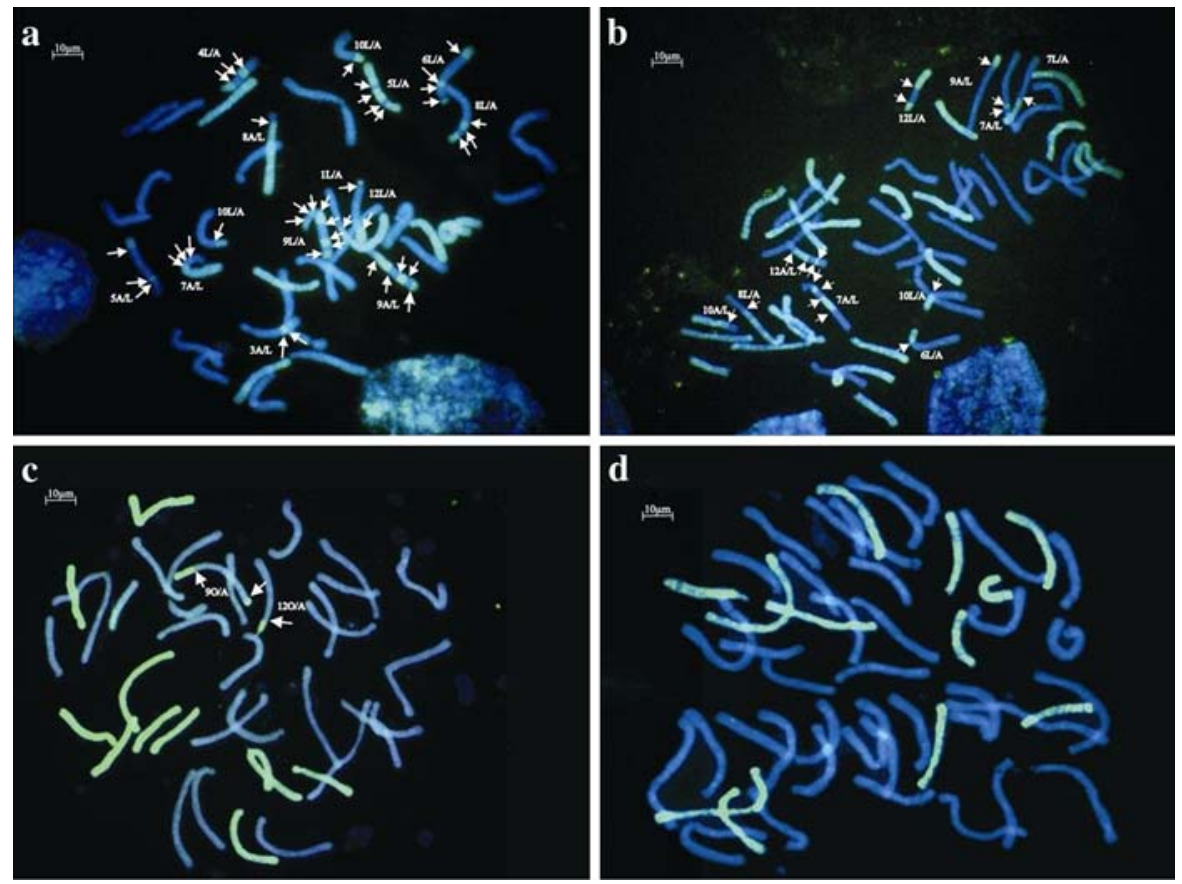

Fig. 1 a-d Triploid $(2 n=3 x=36)$ and tetraploid $(2 n=4 x=48)$ LA and OA hybrids obtained from uni- and bilateral sexual polyploidization. a Chromosomes complement of triploid BC1 LA (062071-2) showing 12 L and 24 A chromosomes. b Chromosomes complement of tetraploid F2 LA (064534-1) showing $25 \mathrm{~L}$ and $23 \mathrm{~A}$ chromosomes. c Chromosomes complement of triploid BC1 OA (02260536) showing $12 \mathrm{O}$ and $24 \mathrm{~A}$ chromosomes. d Chromosome

obtained from two different parental combinations (Table 2). The ploidy levels of all these progenies were determined through flow cytometry (data not presented) as well as by cytological counting of the chromosomes. Most of the resulting progenies were allotriploid $(2 n=3 x=36)$ indicating the production of functional $2 n$ pollen in F1 OA hybrids.

\section{Bilateral sexual polyploidization}

This was possible only in LA hybrids because of the above stated reason. There was scarcity of genotypes in interspecific lily hybrids which produce both $2 n$ eggs and $2 n$ pollen simultaneously. So sib-matings were made between F1 LA hybrids which were found to produce either $2 n$ eggs or $2 n$ pollen in order to get an F2 population. Three F1 LA hybrids which produced $2 n$ eggs were used as female parents and crossed with one F1 LA hybrid as male parent which

complement of tetraploid BC1 OA (022605-4) showing $12 \mathrm{O}$ and 36 A chromosomes. Recombination chromosomes are marked with arrow heads indicating three type of recombinant chromosomes i.e., L/A centromere of Longiflorum genome with Asiatic recombinant segments or vise versa $(\mathrm{A} / \mathrm{L})$ and O/A i.e., centromere of Oriental genome with Asiatic recombinant segment

produced $2 n$ pollen. So the resultant progenies were expected to be allotetraploid. As a result of this combination $(\mathrm{LA} \times \mathrm{LA})$ a total of 23 plants were obtained. The ploidy level of all these genotypes was determined through flow cytometry (data not presented) and 16 of these plants were analysed cytologically (Table 3).

\section{Genomic structure of $\mathrm{BC}$ progenies}

Genome composition of LA $\times$ AA and $\mathrm{AA} \times \mathrm{LA}$ progenies

With GISH technique, it was possible to identify the chromosomes of parental genomes and recombinant segments in the progenies (Fig. 1). Table 1 reports genome composition of $\mathrm{BC} 1$ genotypes obtained after unilateral sexual polyploidization. Here F1 LA hybrids 
backcrossed reciprocally with different Asiatic parents to get $\mathrm{LA} \times \mathrm{AA}$ and $\mathrm{AA} \times \mathrm{LA}$ type of progenies, respectively. A total of 48 genotypes where F1 LA hybrid is used as female parent were analysed with GISH. Similarly, 15 genotypes were also investigated where F1 LA hybrid used as male parent. Most of the analysed genotypes were triploid $(2 n=3 x=36)$. This observation of allotriploid $\mathrm{BC} 1$ progenies proved that the F1 LA hybrids had contributed balanced $2 n$ chromosome complement. However, two genotypes had an aneuploid condition $(3 x+1)$ in case of LA $\times$ AA type of cross while in reciprocal cross $(\mathrm{AA} \times \mathrm{LA})$ four aneuploid $(3 x+1$ and -1$)$ genotypes were obtained (Table 1 ). This condition could be explained on the basis of the $2 n+1$ and -1 egg produced in the F1 LA hybrids. In a majority of the triploid BC1 LA progeny plants, 12 chromosomes of the L genome and 24 of the A genome were clearly identified (in the case of recombinant chromosomes only the centromere was taken into consideration). However, there were four genotypes (062071-2, 066960-6, 066960-20, 066994-3) recovered in LA $\times$ AA progeny where there was deviation from the expected $12 \mathrm{~L}$ and $24 \mathrm{~A}$ chromosomes, respectively, (Table 1). On the other hand 8 genotypes were found in case of AA $\times$ LA cross where there were 12 $(12+1,+2$ or $12-1,-2) \mathrm{L}$ and $24(+1,-1$ and -2$) \mathrm{A}$ chromosomes, respectively. As far as recombination was concerned most of the BC1 LA hybrids exhibited recombination to certain extent. An illustration of these triploid genotypes is given (Fig. 1a).

\section{Genome composition of the AA $\times$ OA progenies}

A total of $53 \mathrm{BC} 1$ progenies resulting from OA hybrids through unilateral sexual polyploidization were analysed during the present investigation. It was found that $48(90.38 \%)$ genotypes were triploid $(2 n=3 x=36)$, four $(7.7 \%)$ were tetraploid $(2 n=4 x=48)$ and one $(1.92 \%)$ was aneuploid $(3 x+1)$. As expected the triploid $\mathrm{BC} 1$ progenies of the OA hybrids indicated that the F1 OA hybrid donated $2 n$ gametes to the progeny so that a complete set of OA chromosomes were transferred to their subsequent progenies. Most of the $\mathrm{BC} 1$ triploids had $24 \mathrm{~A}$ and $12 \mathrm{O}$ chromosomes. However, like in LA hybrids, three genotypes in $\mathrm{BC} 1$ triploid progenies of OA hybrids were found to possess $(12+1$ or -1$)$ of $\mathrm{O}$ chromosomes from the expected $12 \mathrm{O}$ - and $24 \mathrm{~A}$-genome chromosomes (Table 2). The four tetraploids recovered had originated through the functioning of $2 n$ eggs from the female Asiatic parents and hence contributed two sets of the A genome. Remarkably, one of these plants (022605-13) had $11 \mathrm{O}$ and $37 \mathrm{~A}$ chromosomes instead of the expected 12 $\mathrm{O}+36$ A constitutions. One aneuploid $(3 x+1)$ was also found in the $\mathrm{BC} 1$ progenies with one extra chromosome of A genome. This could have resulted from a univalent which might have lagged behind when the sister chromatids of the other univalents were segregating during FDR process of OA hybrid parents. This gave rise to the formation of $2 n+1$ gametes (Table 2). Figure 1 (c and d) shows the triploid and tetraploid genotypes, respectively, with recombinant chromosomes.

Genome composition of LA $\times$ LA hybrids

A total of $16 \mathrm{~F} 2$ plants derived from crossing LA hybrids that produced either $2 n$ eggs or $2 n$ pollen were analysed by GISH for their ploidy level, number of chromosomes from each genome and the number of recombinant chromosomes (Fig. 1b). It was found that nine genotypes were tetraploids $(2 n=4 x=48)$ indicated the contribution of $2 n$ gametes from both parents. The other seven genotypes (064525-6, -7, -8, $-14,-15,-18$ and 064536-2) had an aneuploid condition with $4 x-4,-5,+5,-1,-3,+1-1$ and -1 , respectively, (Table 3 ).

Homoeologous recombination and frequency of introgression of $\mathrm{L}$ and $\mathrm{O}$ - genomes into A-genome

From the analyzed data, it was found that in case of $\mathrm{BC} 1$ progenies of both LA and OA hybrids obtained from unilateral sexual polyploidization, 56 genotypes $(88.8 \%)$ of $\mathrm{LA} \times \mathrm{AA}$ and its reciprocal cross $(\mathrm{AA} \times \mathrm{LA})$ and $46(86.8 \%)$ of the progenies of OA hybrids exhibited recombination at certain level (Tables 1, 2). It means that there is no significant difference between the two groups of progenies with regard to number of plants with recombinant chromosomes. However, the numbers and frequency of recombinant chromosomes differed depending on the direction of the cross and it is irrespective of the type of interspecific hybrids used for sexual polyploidization. It was found that the frequency of recombination recovered in $\mathrm{BC} 1$ progenies was higher in case of LA 
Fig. 2 A diagrammatic representation of recombinant chromosomes in $\mathrm{BC} 1$ triploid LA (062071-2, 066994-3 and 066995-1) and OA (022605-30, 022605-35 and 022605-46) hybrids. In this figure the black colour represents the Longiflorum and Oriental genomes while white grey represents the Asiatic one
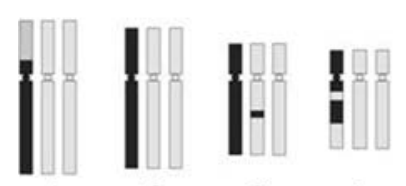

062071-2
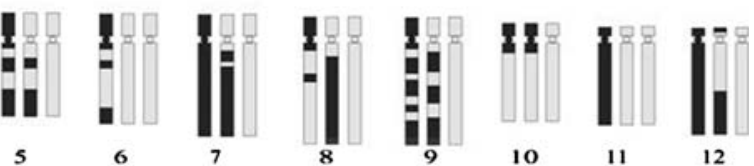

066994-3
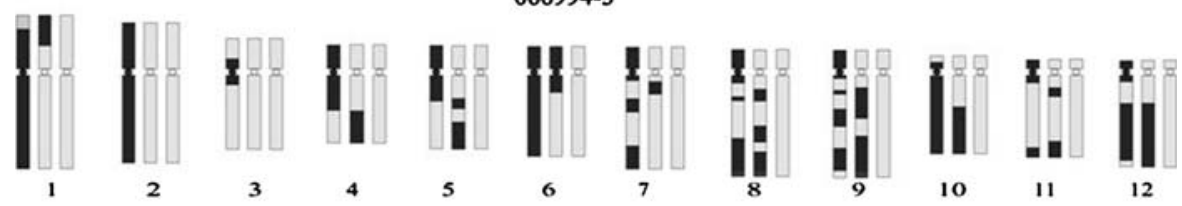

066995-1
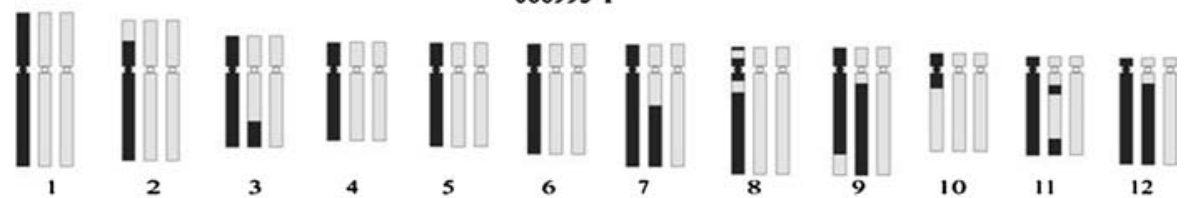

022605-30
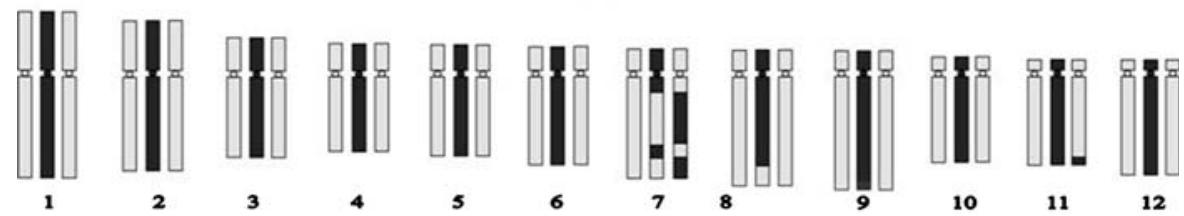

022605-35
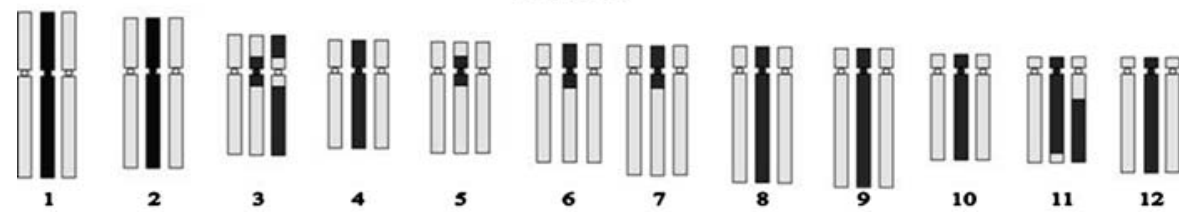

022605-46
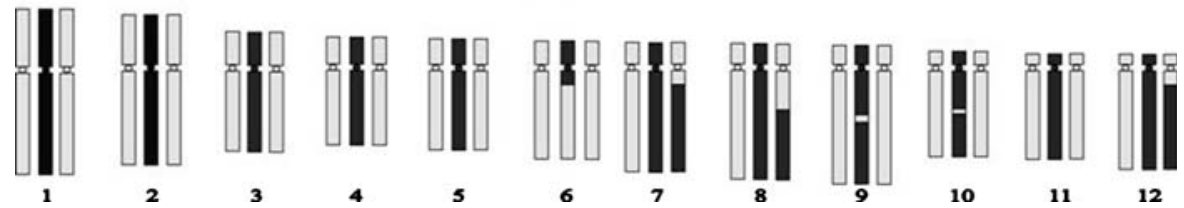

and vice versa, i.e., L/A. Among the $48 \mathrm{BC} 1 \mathrm{LA}$

hybrids (when F1 LA hybrids were used as female parents) as compared to OA hybrids where $2 n$ gametes were donated by the male parent. Similarly the frequencies of recombination events were also higher in LA hybrids than OA hybrids.

There were obviously four type of chromosomes; two non-recombinant chromosomes, $\mathrm{L}$ and $\mathrm{A}$ and two recombinant chromosomes L/A and $\mathrm{A} / \mathrm{L}$. Those with a centromere of Asiatic chromosome with introgression of Longiflorum segments, are indicated as $\mathrm{A} / \mathrm{L}$, genotypes which were derived from a cross where F1 LA hybrids were used as female parent, a total of 271 recombinant chromosomes were detected. Out of these 271 recombinant chromosomes, 148 were L/A types and 123 were of $\mathrm{A} / \mathrm{L}$ type. This contrasted with the 35 recombinant chromosomes recovered in 15 triploid $\mathrm{BC} 1$ progenies of LA hybrids where F1 LA hybrids were used as male parent. Here 13 chromosomes were of $\mathrm{L} / \mathrm{A}$ and 22 were of $\mathrm{A} / \mathrm{L}$ types 
(Table 1). Similarly in case of OA hybrids four type of chromosomes; two non-recombinant chromosomes, $\mathrm{O}$ and $\mathrm{A}$ and two recombinant chromosomes $\mathrm{O} / \mathrm{A}$ and $\mathrm{A} / \mathrm{O}$. In case of $\mathrm{BC} 1$ progenies of $\mathrm{OA}$ hybrids a total of 179 recombinant chromosomes were recovered where 98 were $\mathrm{O} / \mathrm{A}$ and 81 were of $\mathrm{A} /$ O type of recombinant chromosomes (Table 2). Thus there was an obvious difference between the two types of interspecific hybrid with regard to the contribution of recombinant chromosomes to their resultant progenies depending on the direction of the cross. Furthermore the range of recombinant chromosomes varied from 0 to 20 in the crosses involved F1 LA hybrids as female parent where as in reciprocal cross $(\mathrm{AA} \times \mathrm{LA})$ it ranged from 0 to 6 in various genotypes. On the other hand in case of OA hybrids, the number of recombinant chromosomes was far less than LA $\times$ AA hybrids and it varied from 0 to 8 in different genotypes. As far as the crossover event were concerned there were evidences that single, double and multiple crossover events had occurred in both type of progenies resulting from unilateral sexual polyploidization.

In case of progenies derived from bilateral sexual polyploidization $(\mathrm{LA} \times \mathrm{LA}) 14$ genotypes $(87.5 \%)$ exhibited recombinant chromosomes. The total number of recombinant chromosomes recovered in F2 progeny derived from $2 n-2 n$ cross was 56 . Here 31 of these were L/A type while 25 were $\mathrm{A} / \mathrm{L}$ type of recombinant chromosomes (Table 3).

Taking the total length of three genomes i.e., A, L and $\mathrm{O}$ genomes in the $\mathrm{BC} 1$ triploid progenies, the percentages of each genome present in the $\mathrm{BC} 1$ progenies was estimated (Tables 1,2 ). There is a little deviation from the expected values $(\mathrm{L}=33.3 \%$ and $\mathrm{A}=66.7 \%)$. The percentage of $\mathrm{L}$ genome varied from $29.98 \%$ (066960-8) to as high as $37.01 \%$ (066995-1). Similarly, in case of OA hybrids the amount of introgression of $\mathrm{O}$ genome in $\mathrm{A}$ also ranged from 20 (022605-3) to $36.92 \%$ (022605.46). In order to estimate the number and types of recombinant chromosomes and the lengths of recombinant segments, the karyotypes of some of the $\mathrm{BC} 1$ LA and OA progenies were determined and shown in Fig. 2. However, in most of the cases almost an expected amount of Longiflorum and Oriental genomes were transmitted from LA and OA hybrids to respective $\mathrm{BC} 1$ progenies resulted from unilateral sexual polyploidization.

\section{Discussion}

Role of $2 n$ gametes in intergenomic recombination and introgression

Present study revealed that unilateral and bilateral sexual polyploidization through $2 n$ gametes could successfully be carried out in interspecific lily (Lilium) hybrids to produce allotriploid and allotetraploid genotypes. Application of functional $2 n$ gametes has become an important tool for the production of polyploid cultivars in different plant species like potato (Mendiburu and Peloquin 1977; Den Nijs and Peloquin 1977), wheat (Jauhar 2003), Lolium (Sala et al. 1989), Aspagarus (Camadro 1994), Medicago sativa (Barcaccia et al. 1998) and Lilium (Lim et al. 2001; Barba-Gonzalez et al. 2005; Zhou et al. 2008). The traditional method to breed the triploid lilies is to obtain the tetraploid as a first step by mitotic polyploidization. These tetraploids are then crossed with normal diploids to achieve triploid progenies. This approach is less desirable because in the allotetraploid, which behaves like a 'permanent hybrid' due to autosyndetic chromosome pairing, no intergenomic recombination is expected to occur. As a result, there is very little scope for the selection of cultivars from mitotic polyploidization. On the other hand the breeding schemes involving $2 n$ gametes via unilateral sexual polyploidization in lily hybrids can overcome F1 hybrid sterility, facilitate intergenomic recombination leading to genetic variation and production of allotriploid progenies with some introgressed chromosomal segments. This has been clearly demonstrated in three different types of interspecific hybrids: Longiflorum $\times$ Asiatic (Lim et al. 2003; Zhou et al. 2008), Oriental $\times$ Asiatic (Barba-Gonzalez et al. 2004) and L. auratum $\times L$ henryi (Van Tuyl et al. 2002). During present study, allotriploid progenies were obtained in LA and OA hybrids through functional $2 n$ eggs as well as $2 n$ pollen. Previously, in most of the cases $2 n$ pollen rather than $2 n$ eggs have been used for unilateral sexual polyploidization. One reason might be that it is easier to detect $2 n$ pollen producing genotypes merely by staining the pollen and determine the size or growing them on artificial pollen germination medium. On the other hand, detection of $2 n$ egg requires crossing and production of progeny that has to be tested for ploidy level. Although we have 
selected several interspecific F1 hybrids that produce either $2 n$ pollen or $2 n$ eggs, the frequencies of such genotypes are relatively low as compared to other liliaceous such as Alstroemeria and other plants (Kamstra et al. 1999a, b; Ramanna et al. 2003; Ramsey and Schemske 1998).

\section{Unilateral sexual polyploidization}

The development of GISH technique facilitates discrimination of the parental genomes and predicts the level and amount of genome changes that occur in such crosses. Earlier reports on analysis of microsporogenesis during $2 n$ pollen formation indicated the meiotic irregularities leading to the generation of gametes with differing genome compositions depending on the types of meiotic nuclear restitution (Lim et al. 2001; Ramanna and Jacobsen 2003; BarbaGonzalez et al. 2004).

The first objective of our study was to produce interspecific triploid lilies (LA and OA) through $2 n$ gametes (both male and female) via unilateral sexual polyploidization and to evaluate the nature of these BC1 triploid progenies by GISH. In this study, we have demonstrated the frequency of homoeologous recombination and amount of introgression from Land $\mathrm{O}$-genomes into $\mathrm{A}$ genome when $\mathrm{BC} 1$ progenies were obtained after unilateral sexual polyploidization. Flow cytometric analysis (data not presented) and chromosome counting after GISH confirmed the allotriploid natures of $\mathrm{BC} 1$ plants in both type of crosses, i.e. $\mathrm{LA} \times \mathrm{AA}$ and $\mathrm{OO} \times \mathrm{AA}$. In case of $\mathrm{BC} 1$ progenies of LA hybrids $(\mathrm{LA} \times \mathrm{AA}$ type of cross), most of the genotypes were triploid $(2 n=3 x=36)$ where 24 chromosomes were contributed by $2 n$ gametes producing LA hybrid and $n$ number of chromosomes by the Asiatic parent. As a result 24 chromosomes inherited from $\mathrm{A}$ and 12 chromosomes from $\mathrm{L}$ genome were present in $\mathrm{BC} 1$ progeny plants. However, it was found that in some $\mathrm{BC} 1 \mathrm{LA}$ hybrid $(\mathrm{LA} \times \mathrm{AA}$ and $\mathrm{AA} \times \mathrm{LA})$ there were deviation from the expected number of $L$ and $A$ chromosomes. This deviation could be explained on the bases of IMR mechanism of $2 n$ gametes formation in LA hybrids (Lim et al. 2001). In case of BC1 progeny of OA hybrid, the progenies are mostly triploids $(2 n=3 x=36)$ with few tetraploid genotypes. These tetraploid progenies could be the result of bilateral sexual polyploidization. Here, mostly we found the normal contribution of $24 \mathrm{~A}$ ( $2 n$ pollen contribute each set of $12 \mathrm{O}$ and $12 \mathrm{~A}$ chromosomes) and $12 \mathrm{O}$ genome composition in $\mathrm{BC} 1$ plants with few exception of $12+1$ or $-1 \mathrm{O}$ chromosomes. This indicates that FDR was the mechanism of $2 n$ gametes formation in most of OA hybrids (Ramanna et al. 2003; Barba-Gonzalez et al. 2004). Present study strengthens the findings of Lim et al. (2001), BarbaGonzalez et al. (2005) and Zhou et al. (2008) who found that in case of both LA and OA hybrids more $\mathrm{BC} 1$ progenies recovered from FDR $2 n$ gametes rather than IMR $2 n$ gametes. This might be due to more stability and viability of FDR $2 n$ gametes as compared to IMR $2 n$ gametes in both types of F1 hybrids.

GISH analysis of $\mathrm{BC} 1$ progenies has demonstrated an extensive genome recombination in the $\mathrm{BC} 1$ progenies of both LA and OA hybrids obtained after unilateral sexual polyploidization. It was found that the choice of female parents producing $2 n$ gametes also has a significant effect as compared to $2 n$ gametes producing male parent when backcrossed to a diploid Asiatic cultivars. This significant effect was in terms of the numbers of recombinant chromosomes recovered in allotriploid $\mathrm{BC} 1$ progenies. When $\mathrm{F} 1$ LA hybrids were used as female parents and backcrossed with diploid Asiatic cultivars a large numbers of intergenomic recombinants were recovered in $\mathrm{BC} 1$ progenies of LA hybrids. However, lower numbers of recombinant chromosomes were obtained in $\mathrm{BC} 1$ progenies of both LA and OA when these F1 interspecific hybrids were used as male parents. These differences amongst the rate of recombination between male and female parents are in accordance with the findings of Lagercrantz and Lydiate (1995) and Labonne et al. (2007) who found that there is an increase in the rate of recombination during female meiosis as compared to male meiosis in Brassica nigra and Tunera krapovickasii $\times T$. subulata interspecific hybrid, respectively. It was found that 43 of the analysed plants $(89.5 \%)$ of $\mathrm{BC} 1$ progeny of LA $\times$ AA had recombinant chromosomes in variable numbers i.e., 1-20 recombinant chromosomes per genotype. While in the reciprocal crosses 12 genotypes $(80 \%)$ had recombinant chromosomes ranged from 1 to 6 recombinant chromosomes per genotype. Moreover, on average $15.7 \%$ recombinant chromosomes have been recovered in $\mathrm{BC} 1$ triploid progeny of $\mathrm{LA} \times \mathrm{AA}$ crosses while the recovery of 
recombinant chromosomes in the reciprocal crosses was $6.5 \%$. Similarly when OA F1 hybrids were used as male parent and backcrossed with a diploid Asiatic cultivar 46 out of 53 analysed BC1 plant (86.8\%) exhibited recombinant chromosomes. In contrast when OA hybrid is used as male parent the number of recombinant chromosomes is far less (1-8) than in the corresponding progeny of LA hybrids where F1 LA hybrids were used as female parent. However, the number of recombinant chromosomes is almost the same when LA hybrids were used as pollen donors (i.e. 1-6). Similarly, the average number of recombinant chromosomes recovered in OA hybrids is almost the same $(8.9 \%)$ when compared with the BC1 LA progenies $(6.5 \%)$ obtained when LA hybrids were used as male parents The mean result of analysed genotypes in both types of crosses clearly reflected the low recombination events in LA and OA hybrids where F1 interspecific hybrids used as pollen donors as compared to LA hybrids where F1 hybrids contributed $2 n$ eggs.

Barba-Gonzalez et al. (2004) found that some other F1 OA hybrids and Asiatic cultivars also produced $2 n$ gametes and they resulted in the production of triploid and tetraploid progenies. However, it was found that when OA hybrids were backcrossed with Oriental cultivars only triploid progenies were obtained. GISH analysis proved that not only F1 OA hybrid studied here (951502-1; Table 2) resulted into intergenomic recombination but another F1 OA hybrid 952400-1 also resulted in chromosomal recombination in $\mathrm{BC} 1$ progenies when back crossed with some of the Asiatic cultivars (Barba-Gonzalez et al. 2005). Similarly, it was found that LA hybrids produced $2 n$ gametes and used either as male or female parents to get allotriploid progenies with certain amount of intergenomic recombination when backcrossed with various Asiatic cultivars (Zhou et al. 2008; Khan et al. 2009).

In the current study, it was found that more or less the expected percentage (33.3\%) of L and $\mathrm{O}$ genome is retained in $\mathrm{BC} 1$ progenies of LA and OA hybrids. However, irrespective of the direction and type of the cross, an imbalance was found between numbers of L- and O- genome introgressions on A chromosomes and vice versa. The karyotypes for all LA and OA hybrids were constructed (an example is given in Fig. 2). It was found that in case of LA hybrids there were a total of 271 recombinant chromosomes (148
L/A and $123 \mathrm{~A} / \mathrm{L}$ types). Some of these recombinant chromosomes are the reciprocal products i.e. L/A-A/ $\mathrm{L}$ so they had equal contribution of introgressed segments from both genomes. However, non reciprocal recombinant products were also obtained. It was found that in these non reciprocal products in both type of crosses (LA and OA) the Asiatic genome introgression on $\mathrm{L}$ or $\mathrm{O}$ chromosomes is exceeded. Conversely, less introgression of $\mathrm{L}$ or $\mathrm{O}$ genome was found in Asiatic background. In LA $\times$ AA crosses, a total of 125 Asiatic introgressions were found on $\mathrm{L}$ genome while introgressions of L genome on Asiatic chromosomes was 85. Similarly in AA $\times$ OA hybrids a total of $57 \mathrm{~A}$ genome introgression were found on $\mathrm{O}$ chromosomes while in reciprocal case 42 introgressions were found in Asiatic background from $\mathrm{O}$ genome.

\section{Bilateral sexual polyploidization}

Another aim of the present study was to evaluate the relevance of bilateral sexual polyploidization in interspecific lily hybrids. However, it is worthy to have genotypes producing $2 n$ gametes for the bilateral sexual polyploidization. In the absence of genotypes of lily hybrids that produce both $2 n$ pollen and $2 n$ eggs simultaneously, bilateral sexual polyploidization in interspecific lily hybrids has not been accomplished before. One idea was to use the F1 hybrid with good female fertility to be crossed with another F1 hybrid with good male fertility to produce tetraploids through bilateral sexual polyploidization. These ideas became evident only when the crosses were made between some F1 LA hybrids through sibmating to generate F2 population. Such tetraploids have two important advantages: (1) Because of their fertility they can be used as parents repeatedly to produce triploid or tetraploid progenies. (2) When the bilateral sexual polyploids possess recombinant chromosomes, they are likely to pair as multivalents and segregate randomly as if in an autopolyploid. This means, the loci present on recombinant chromosomes segregate whereas all other loci will not segregate as in the typical allotetraploid (Ramanna et al. 2003). Furthermore, using this method of sexual polyploidization, crops with maximum heterozygosity could replace those obtained by artificial chromosome doubling (Den Nijs and Stephenson 1988; Hahn et al. 1990; McCoy 1992). Because of these 
attributes, such tetraploids might be potentially useful for introgression and for cytogenetic mapping purposes. The present study implies that crosses between parents producing $2 n$ gametes produced allotetraploid progenies and in the following backcross $4 x$ and $2 x$ parents would predominantly produce triploid progenies in the $4 x-2 x$ direction.

As mentioned earlier bilateral sexual polyploidization is rarer than its unilateral counterpart, the few known cases involved were Trifolium pratense (Parrott et al. 1985), Solanum (Jongedijk et al. 1991; Werner and Peloquin 1991), Avena sativa haploids (Rines and Dahleen 1990), Dactylis glomerata L. (Van Santen et al. 1991; Lumaret et al. 1992), Triticum-Aegilops hybrids (Fukuda and Sakamoto 1992), Madicago spp. (Barcaccia et al. 1998), Triticum turgidum haploids (Jauhar et al. 2000), Manihot esculenta (Ogburia et al. 2002), and Alstroemeria (Ramanna et al. 2003).

Harlan and de Wet (1975) pointed out the three mechanism responsible for polyploid formation viz. (1) by direct unilateral or bilateral sexual polyploidization by fusion of $2 n$ gametes (2) by an intermediate step forming a hybrid with $2 n$ gamete and (3) somatic doubling of diploid hybrid. It was argued that for direct bilateral sexual polyploidization, the mean frequency of $2 n$ gamete production in a diploid population is so low that the chance of spontaneous tetraploidization, by fusion of two $2 n$ gametes is negligible. However, some spontaneous bilateral sexual polyploids have been reported in Manihot esculenta (Hahn et al. 1990), Dactylis glomerata (Van Santen et al. 1991) and Cyphomandra betacea (Pringle and Murray 1992). It was found in the present study that interspecific F1 LA hybrids produced both $2 n$ pollen and $2 n$ eggs resulted in tetraploid or near tetraploid (aneuploid) progenies (Table 3). Irregular segregation of sister chromatids during FDR can produce $2 n+1$ or $2 n-1$ gametes. The fusion of such gametes can produce near tetraploid (aneuploid) progenies.

Unilateral and bilateral sexual polyploidization resulted in the formation of triploid and allotetraploid progenies, respectively. A general consideration is that those triploids are mostly sterile and have little interest in breeding because of sterility. However, a cursory look at the literature indicates that triploid have been used successfully in crossing programs and could produce diploid or circa diploid progenies in
$3 x-2 x$ or in reciprocal crosses (Lim et al. 2003; Barba-Gonzalez et al. 2006b; Proscevičius et al. 2007). These diploid or circa diploid progenies are potentially useful for breeding at the diploid level (Khan et al. 2009). Unlike the triploids the allotetraploids obtained after bilateral sexual polyploidization could be fertile and can produce progenies by selfing or crossing with other genotypes.

Different interspecific F1 hybrids with $2 x-2 x$ crosses were made to estimate the $2 n$ gametes formation. When no natural polyploids are available, certain treatments are done to induce the $2 n$ gametes formation. Notably temperature and chemical agents were shown to affect the frequency of $2 n$ gamete formation (Bretagnolle and Thompson 1995; Ramsey and Schemske 1998; Barba Gonzalez et al. 2006a; $\mathrm{Wu}$ et al. 2007). Beside these factors the production of $2 n$ gametes is under strong influence of genetic control (Bretagnolle and Thompson 1995; Ramsey and Schemske 1998). Recently, the first gene AtPSI responsible for $2 n$ gametes formation has been isolated and characterized (d'Erfurth et al. 2008). This information can facilitate our understanding the origin of $2 n$ gametes and speed up their use in crop breeding programs.

Acknowledgments We are thankful to Dr. Shujun Zhou (Zhejiang University, China) for his contribution in GISH analysis. Thanks to Dutch lily breeding companies (De Jong Lelies BV, Royal Van Zanten BV, Testcentrum voor Siergewassen BV, Vletter and Den Haan BV and World Breeding BV) who supplied part of the plant material and the Dutch Commodity Board for Horticulture who financially supported this project.

Open Access This article is distributed under the terms of the Creative Commons Attribution Noncommercial License which permits any noncommercial use, distribution, and reproduction in any medium, provided the original author(s) and source are credited.

\section{References}

Barba Gonzalez R, Miller CT, Ramanna MS, Van Tuyl JM (2006) Nitrous oxide $\left(\mathrm{N}_{2} \mathrm{O}\right)$ induces $2 n$ gametes in sterile F1 hybrids of Oriental $\times$ Asiatic lilies (Lilium) and leads to intergenomic recombination. Euphytica 148:303-309

Barba-Gonzalez R, Lokker BH, Lim K-B, Ramanna MS, Van Tuyl JM (2004) Use of $2 n$ gametes for the production of sexual polyploids from sterile Oriental $\times$ Asiatic hybrids of lilies (Lilium). Theor Appl Genet 109:1125-1132

Barba-Gonzalez R, Lim K-B, Ramanna MS, Visser RGF, Van Tuyl JM (2005) The occurrence of intergenomic 
recombination in the $\mathrm{F} 1$ hybrid of Oriental $\times$ Asiatic lily hybrids (Lilium) and its significance for genetic variation in the $\mathrm{BC} 1$ progenies as revealed by GISH and FISH analysis. Genome 48:884-894

Barba-Gonzalez R, Van Silfhout A, Visser RGF, Ramanna MS, Van Tuyl JM (2006) Progenies of allotriploids of Oriental $\times$ Asiatic lilies (Lilium) examined by GISH analysis. Euphytica 151:243-250

Barcaccia G, Rosellini D, Falcinelli M, Veronesi F (1998) Reproductive behaviour of tetraploid alfalfa plants obtained by unilateral and bilateral sexual polyploidization. Euphytica 99:199-203

Barthes L, Ricroch A (2001) Interspecific chromosomal rearrangements in monosomic addition lines of Allium. Genome 44:929-935

Bastiaanssen HJM, Van Den Berg PMMM, Lindhout P, Jacobsen E, Ramanna MS (1998) Postmeiotic restitution in $2 n$-egg formation of diploid potato. Heredity 81:20-27

Becerra Lopez-Lavalle LA, Orjeda G (2002) Occurrence and cytological mechanism of $2 n$ pollen formation in a tetraploid accession of Ipomoea batatas (Sweet Potato). J Hered 93:185-192

Bingham ET (1980) Maximising heterozygosity in autopolyploids. In: Lewis WH (ed) Polyploidy-biological relevance. Plenum Press, New York, pp 471-490

Bremer G (1961) Problems in breeding and cytology of sugarcane. Euphytica 10:59-78

Bretagnolle F, Thompson JD (1995) Gametes with the somatic chromosome number: mechanisms of their formation and role in the evolution of autopolyploid plants. New Phytol 129:1-22

Bringhurst RS, Voth V (1984) Breeding octoploid strawberries. Iowa State J Res 58:371-381

Camadro EL (1994) Second meiotic division restitution (SDR) $2 \mathrm{n}$ pollen formation in diploid and hexaploid species of Asparagu. Genet Resour Crop Evol 41:1-7

d'Erfurth I, Jolivet S, Froger N, Catrice O, Novatchkova M, Simon M, Jenczewski E, Mercier R (2008) Mutations in AtPS1 (Arabidopsis thaliana Parallel Spindle 1) lead to the production of diploid pollen grains. PLoS Genet 4: e1000274

De Wet JMJ (1980) Origins of polyploids. In: Lewis WH (ed) Polyploidy: biological relevance. Plenum Press, London, pp 3-15

Den Nijs TPM, Peloquin SJ (1977) $2 n$ gametes in potato species and their function in sexual polyploidization. Euphytica 26:585-600

Den Nijs APM, Stephenson AG (1988) Potential of unreduced pollen for breeding tetraploid perennial ryegrass. In: Cresti M, Gori P, Pacini E (eds) Sexual reproduction in higher plants. Springer, Berlin, pp 131-136

Fukuda K, Sakamoto S (1992) Studies on unreduced gamete formation in hybrids between wheats and Aegilops squarrosa L. Hereditas 116:253-255

Hahn SK, Bai KV, Asiedu R (1990) Tetraploids, triploids and $2 n$ pollen from diploid interspecific crosses with cassava. Theor Appl Genet 79:433-439

Hall HK (1990) Blackberry breeding. Plant Breed Rev 8: 249-312

Harlan JR, De Wet HMJ (1975) On Ö Winge and a prayer: the origins of polyploidy. Bot Rev 41:361-390
Jackson RC (1976) Evolution and systematic significance of polyploidy. Annu Rev Ecol Syst 7:209-234

Jauhar PP (2003) Formation of $2 n$ gametes in durum wheat haploids: Sexual polyploidization. Euphytica 133:81-94

Jauhar PP, Dogramaci-Altuntepe M, Peterson TS, Almouslem AB (2000) Seedset on synthetic haploids of durum wheatcytological and molecular investigations. Crop Sci 40:1742-1749

Jongedijk E, Ramanna MS, Sawor Z, Hermsen JGT (1991) Formation of first division restitution FDR $2 n$-megaspores through pseudohomotypic division in $\mathrm{ds} 1$ desynapsis mutants of diploid potato: Routine production of tetraploid progeny from 2x FDR-2x FRD crosses. Theor Appl Genet 82:645-656

Kamstra SA, Kuipers AGJ, De Jeu MJ, Ramanna MS, Jacobsen E (1999a) The extent and position of homoeologous recombination in a distant hybrid of Alstroemeria: a molecular cytogenetic assessment of first generation backcross progenies. Chromosoma 108:52-63

Kamstra SA, Ramanna MS, de Jeu MJ, Kuipers AGJ, Jacobsen E (1999b) Homoeologous chromosome pairing in the distant hybrid Alstroemeria aurea $\times A$ inodora and the genome composition of its backcross derivatives determined by fluorescence in situ hybridization with species specific probes. Heredity 82:69-78

Khan N, Zhou S, Ramanna MS, Arens P, Herrera J, Visser RGF, Van Tuyl JM (2009) Potential for analytic breeding in allopolyploids: an illustration from Longiflorum $\times$ Asiatic hybrid lilies (Lilium). Euphytica 166:399_ 409

Labonne JDJ, Hilliker AJ, Shore JS (2007) Meiotic recombination in Turnera (Turneraceae): extreme sexual difference in rates, but no evidence for recombination suppression associated with the distyly $(S)$ locus. Heredity 98:411-418

Lagercrantz U, Lydiate DJ (1995) RFLP mapping in Brassica nigra indicates differing recombination rates in male and female meiosis. Genome 38:255-264

Lim K-B, Chung J-D, Van Kronenburg BCE, Ramanna MS, De Jong JH, Van Tuyl JM (2000) Introgression of Lilium rubellum Baker chromosomes into L. longiflorum Thunb.: a Genome painting study of the F1 hybrid, BC1 and BC2 progenies. Chromosome Res 8:119-125

Lim K-B, Ramanna MS, De Jong JH, Jacobsen E, Van Tuyl JM (2001) Indeterminate meiotic restitution (IMR): a novel type of meiotic nuclear restitution mechanism detected in interspecific lily hybrids by GISH. Theor Appl Genet 103:219-230

Lim KB, Ramanna MS, Jacobsen E, Van Tuyl JM (2003) Evaluation of $\mathrm{BC} 2$ progenies derived from $3 \mathrm{x}-2 \mathrm{x}$ and $3 \mathrm{x}-$ $4 \mathrm{x}$ crosses of Lilium hybrids: a GISH analysis. Theor Appl Genet 106:568-574

Lumaret R, Bretagnolle F, Maceira NO (1992) $2 n$ gamete frequency and bilateral polyploidization in Dactylis glomerata L. In: Mariani A, Tavoletti S (eds) Gametes with somatic chromosome number in the evolution and breeding of polyploid polysomic species: achievements and perspectives. Porziuncola, Assisi, pp 15-21

Lyrene PM, Vorsa N, Ballington JR (2003) Polyploidy and sexual polyploidization in the genus Vaccinium. Euphytica $133: 27-36$ 
McCoy TJ (1992) Genome manipulation and molecular genetic analysis of alfalfa (Medicago sativa $\mathrm{L}$ ). In: Mariani A, Tavoletti S (eds) Gametes with somatic chromosome numbers in the evolution and breeding of polyploidy polysomic species: achievements and prospectives. Perugia, Italy, pp 55-59

Mendiburu AO, Peloquin SJ (1971) High yielding tetraploids from $4 x-2 x$ and $2 x-2 x$ matings. Am Potato J 48:300-301

Mendiburu AO, Peloquin SJ (1976) Sexual polyploidisation and depolyploidisation: some terminology and definitions. Theor Appl Genet 48:137-143

Mendiburu AO, Peloquin SJ (1977) The significance of $2 n$ gametes in potato breeding. Theor Appl Genet 49:53-61

Mendiburu AO, Peloquin SJ, Mok DWS (1974) Potato breeding with haploids and $2 n$ gametes. In: Kasha KJ (ed) Haploids in higher plants. Guelph University Press, Guelph, pp 249-258

Mok DWS, Peloquin SJ (1972) Three mechanisms of $2 n$ pollen formation in diploid potatoes. Am Potato J 49:362-363

Ogburia MN, Yabuya T, Adachi T (2002) A cytogenetic study of bilateral sexual polyploidization in cassava (Manihot esculenta Crantz). Plant Breed 121:278-280

Ortiz R (1997) Occurrence and inheritance of $2 n$ pollen in Musa. Ann Bot 79:449-453

Ortiz R, Vuylsteke D (1995) Factors influencing seed set in triploid Musa spp. L. and production of euploid hybrids. Ann Bot 75:151-155

Parrott WA, Smith RR (1984) Production of 2n pollen in red clover. Crop Sci 24:469-472

Parrott WA, Smith RR, Smith MM (1985) Bilateral sexual tetraploidization in red clover. Can J Genet Cytol 27:64-68

Peloquin SJ, Ortiz R (1992) Techniques for introgressing unadapted germplasm to breeding populations. In: Stalker HT, Murphy JP (eds) Plant breeding in the 1990s. CAB International, Wallingford, pp 485-507

Pringle GJ, Murray BG (1992) Polyploidy and aneuploidy in the tamarillo, Cyphomandra betacea (Cav.) Sendt. (Solanaceae) I: spontaneous polyploidy and features of the euploids. Plant Breed 108:132-138

Proscevičius J, Rančelienè V, Dambrauskaitė D (2007) Cytogenetic analysis of progeny derived from allotriploid inter-specific hybrids of Lilium. Biologija 53:8-12

Ramanna MS (1979) A re-examination of the mechanisms of $2 n$ gametes formation in potato and its implications for breeding. Euphytica 28:537-561

Ramanna MS, Jacobsen E (2003) Relevance of sexual polyploidization for crop improvement. Euphytica 133:3-18

Ramanna MS, Kuipers AGJ, Jacobsen E (2003) Occurrence of numerically unreduced $(2 n)$ gametes in Alstroemeria interspecific hybrids and their significance for sexual polyploidisation. Euphytica 133:95-106

Ramsey J, Schemske DW (1998) Pathways, mechanisms and rates of polyploid formation in flowering plants. Annu Rev Ecol Syst 98:467-501

Reeves A, Tear J (2000) MicroMeasure for Windows, version 3.3. Free program distributed by the authors over the
Internet from http://www.colostate.edu/Depts/Biology/ MicroMeasure

Rines HW, Dahleen LS (1990) Haploid oat plants produced by application of maize pollen to emasculated oat florets. Crop Sci 30:1073-1078

Rogers SO, Bendich AJ (1988) Extraction of DNA from plant tissues. In: Gelvin SB, Schiperoort RA (eds) Plant molecular biology manual. Kluwer Academic Publishers, Dordrecht, pp 1-11

Sala CA, Camadro MT, Salaberry MT, Mendiburu AO (1989) Cytological mechanism of $2 n$ pollen formation and unilateral sexual polyploidisation in Lolium. Euphytica 43: $1-6$

Smith RR, Parrott WA, Smith MM (1985) Interploidy transfer of germplasm in red clover using $2 n$ gametes. Proceedings of the 15th international grassland congress, Kyoto, Japans. pp 246-248

Stalker HT, Moss JP (1987) Speciation, cytogenetics, and utilization of Arachnis species. Adv Agron 41:1-40

Stewart RN (1947) The morphology of somatic chromosomes in Lilium. Am J Bot 34:9-26

Van Santen E, Hugessen PM, Casler MD (1991) Identification and frequency of tetraploid progeny from $2 x-4 x$ and $4 x-2 x$ crosses in Dactylis. Genome 34:273-278

Van Tuyl JM, Boon E (1997) Variation in DNA-content in the genus Lilium. Acta Hortic 430:829-835

Van Tuyl JM, De Jeu MJ (1997) Methods for overcoming interspecific crossing barriers. In: Shivanna KR, Sawhney VK (eds) Pollen biotechnology for crop production and improvement. Cambridge University Press, Cambridge, pp 273-292

Van Tuyl JM, Lim K-B (2003) Interspecific hybridization and polyploidization as tools in ornamental plant breeding. Acta Hortic 612:13-22

Van Tuyl JM, Van Diën MP, Van Creij MGM, Van Kleinwee TCM, Franken J, Bino RJ (1991) Application of in vitro pollination, ovary culture, ovule culture and embryo rescue for overcoming incongruity barriers in interspecific Lilium crosses. Plant Sci 74:115-126

Van Tuyl JM, Chung M-Y, Chung J-D, Lim K-B (2002) Introgression with Lilium hybrids: Introgression studies with the GISH method on $L$. longiflorum x Asiatic, $L$. longiflorum $x$ L. rubellum and L. auratum $x$ L. henryi The lily yearbook of the NALS 55: 17-22, 70-72

Veronesi F, Mariani A, Bingham ET (1986) Unreduced gametes in diploid Medicago and their importance in alfalfa breeding. Theor Appl Genet 72:37-41

Werner JE, Peloquin SJ (1991) Occurrence and mechanisms of $2 n$ egg formation in $2 x$ potato. Genome 23:975-982

Wu H, Zheng S, He Y, Yan G, Bi Y, Zhu Y (2007) Diploid female gametes induced by colchicine in Oriental lilies. Sci Hortic 114:50-53

Zhou S, Ramanna MS, Visser RGF, Van Tuyl JM (2008) Genome composition of triploid lily cultivars derived from sexual polyploidization of Longiflorum $\times$ Asiatic hybrids (Lilium). Euphytica 160:207-215 